\title{
Composite Measures of Impact and Activity in Psoriatic Arthritis: A Conceptual Framework
}

Considerable progress has been made in recent years to improve outcome measurement in psoriatic arthritis (PsA). The Outcome Measures in Rheumatology (OMERACT) initiative has recently endorsed an updated "core outcome set" of disease domains that should be measured in clinical trials and observational studies of PsA ${ }^{1}$. There are also a range of clinical, patient-reported, and composite clinical measures of disease that have been validated for use in PsA ${ }^{2}$. In this setting the Psoriatic Arthritis Impact of Disease (PsAID) measure ${ }^{3}$ has been developed, and a validation study of the PsAID in an Italian cohort of patients has been undertaken. Results of that study are published in this issue of The Journal. Which measures should clinicians use for the assessment of PsA and where does the PsAID fit into the existing collection of measurement tools?

It is first helpful to remind ourselves of what should be measured to adequately identify the clinical spectrum of PsA. It is well established that PsA is a heterogeneous disease affecting multiple disease domains including joints, skin, entheses, spine, nails, eyes, and axial skeleton ${ }^{4}$. Further, we know the disease phenotype varies (polyarthritis, oligoarthritis, spondyloarthritis, mutilans, and distal interphalangeal arthritis), and patients can transition between phenotype during disease course ${ }^{5,6}$. It is, therefore, a challenge to assess this heterogeneous disease and, historically, assessing only peripheral articular disease has underrepresented the totality of disease burden, thus leading to an incomplete understanding of treatment effect on extraarticular domains of disease. There have, therefore, been efforts to develop a composite disease activity measure that identified the wide range of PsA disease expression: and several measures are now available. These candidate composite measures include, but are not limited to, the Disease Activity in Psoriatic Arthritis (DAPSA) ${ }^{7}$, the Psoriatic Arthritis Disease Activity Index (CPDAI) ${ }^{8}$, the Psoriatic Arthritis Disease Activity Score, GRACE measure (initially named the "Arithmetic Mean of Desirability Function," then re-named the "GRACE" after the development study) ${ }^{9}$, and Minimal Disease Activity (MDA) ${ }^{10}$, which is a disease state that is either met or not. These composite measures have been available for a few years, so why is there not yet a consensus on which one to take forward?

There are perhaps 2 reasons we do not yet have consensus. First, feasibility: Some composites are able to identify almost all domains of disease but may be too complex or time consuming for wider uptake while shorter, more feasible measures may not adequately identify the full disease spectrum. Second, it has become apparent that none of the composite activity measures were developed with substantial patient involvement, and thereby may lack full face validity without the "lived experience" of disease reflected in the measure. Thus, it is in this context of existing physician-developed composite measures of disease activity that we can consider the PsAID measure and the study by Di Carlo, et al $^{11}$ reported in this issue.

The PsAID was developed as part of a European League Against Rheumatism initiative to address the underrepresentation of the patient perspective on PsA outcome measures and produce a Patient Reported Outcome Measure (PROM) to identify the patient perspective of PsA in the model of the Rheumatoid Arthritis Impact of Disease (RAID) ${ }^{3,11 a}$. The PsAID was developed with extensive patient involvement from inception, and from trial conduct through to reporting ${ }^{12}$. Two versions of the questionnaire were developed, 1 for clinical practice (PsAID-12) and 1 for clinical trials (PsAID-9). An international cross-sectional and longitudinal validation study was then undertaken to validate the questionnaire. The PsAID was shown to be feasible, reliable, and responsive, but the authors recognized the need for validation in wider cohorts, and as reported in this issue of The Journal, Di Carlo, et al have undertaken such a study.

Di Carlo, et al report a cross-sectional study from 2 Italian tertiary referral centers evaluating the construct validity, reliability, and interpretability of the PsAID-12 in a real-world setting. In this cross-sectional study of 144 patients with PsA, the authors report data supporting the construct validity and reliability of the PSAID. The authors raise some important issues. First, that comorbid fibromyalgia (FM) is associated with higher PsAID scores. This

See PsAID-12 in clinical setting, page 279

Personal non-commercial use only. The Journal of Rheumatology Copyright @ 2017 . All rights reserved. 
is consistent with a recent report from Brikman, et al showing higher scores in many commonly used disease activity measures in PsA including the DAPSA, CPDAI, Health Assessment Questionnaire, Bath Ankylosing Spondylitis Disease Activity Score, and Leeds Enthesitis Index ${ }^{13}$. Further, no patient in the Brikman, et al study with PsA and FM met $\mathrm{MDA}^{13}$. Concurrent FM, therefore, needs to be recognized when assessing PsA, and the potential effect acknowledged when interpreting PROM study results. Di Carlo, et al also propose cutpoints for the PsAID-12 using disease activity cutpoints developed for the DAPSA. Caution should be exercised before wider utilization of the cutpoints, in part because of the aforementioned effect of FM in this study population and in part the small cross-sectional design of the study.

An important part of the report is the proposal of a PsAID skin score. The authors use factor analysis to identify subcomponents in the main structure of the PsAID. Some questions relate primarily to articular disease (such as pain, fatigue, work ability, functional capacity, and sleep disturbance) as distinct from those related to the psychosocial sphere (such as coping, social participation, anxiety, and depression) and, finally, 1 that may relate more toward skin disease (discomfort, embarrassment, and skin). The direction of load in the factor analysis was strong for skin and embarrassment, and weaker for "discomfort," which obtained only a small load toward PsAID skin score $(0.710$ vs 0.521$)$. It may be expected that discomfort is most related to skin disease since the concept did not arise in the RAID study for rheumatoid arthritis (where there was no skin disease). It is also likely that the factor analysis load of discomfort toward the PsAID skin score is weaker than "skin" or "embarrassment" because of the conflicting influence of coexisting articular disease within the discomfort concept. More information is needed here so we can understand the influence of disease activity or severity on such loading. Do disease duration or asynchronous flares of articular disease during skin remission alter the skin PsAID?

Therefore, the study by Di Carlo, et al adds to a body of evidence supporting the validity of the PsAID for use in PsA. The question now for clinicians, observational researchers, and trialists in the field of PsA is how the PsAID, a measure of disease effect, fits in with the established measures of disease activity and candidate composite measures of disease activity. A framework for understanding effect was proposed in The Journal. Sanderson, et $a l^{14}$ described a triad of severity (a term encompassing disease activity and destruction), self-management, and importance, each contributing to the "impact of disease" (Figure 1).

The "Impact Triad" can also help us understand how a composite measure of effect and activity relate to each other. There is certainly considerable conceptual overlap between a measure of effect and a measure of activity. It could be argued that it is conceptually desirable for a measure of

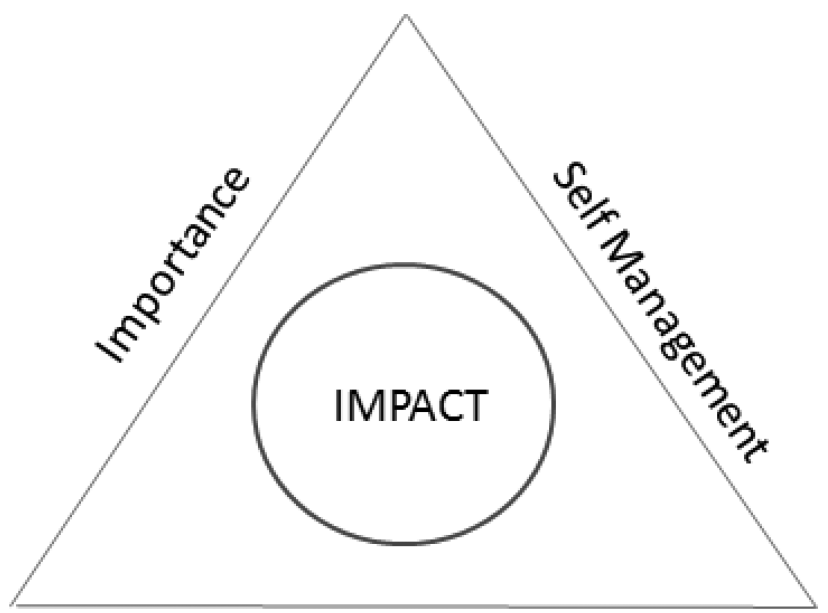

\section{Severity}

Figure 1. The impact triad. From Sanderson, et al. J Rheumatol 2011; 38:191-4; with permission ${ }^{13}$.

disease activity to assess reversible pathophysiological manifestations (activity) rather than potentially irreversible manifestations (such as destruction), or domains that may be influenced by non-disease-related factors (such as self-management). This editorial, therefore, proposes a framework for understanding the relationship between measures of effect and activity through a minor adaptation of the impact triad, whereby the contribution severity is subdivided into activity and damage (Figure 2 ). Such a subdivision recognizes the contribution of both activity and

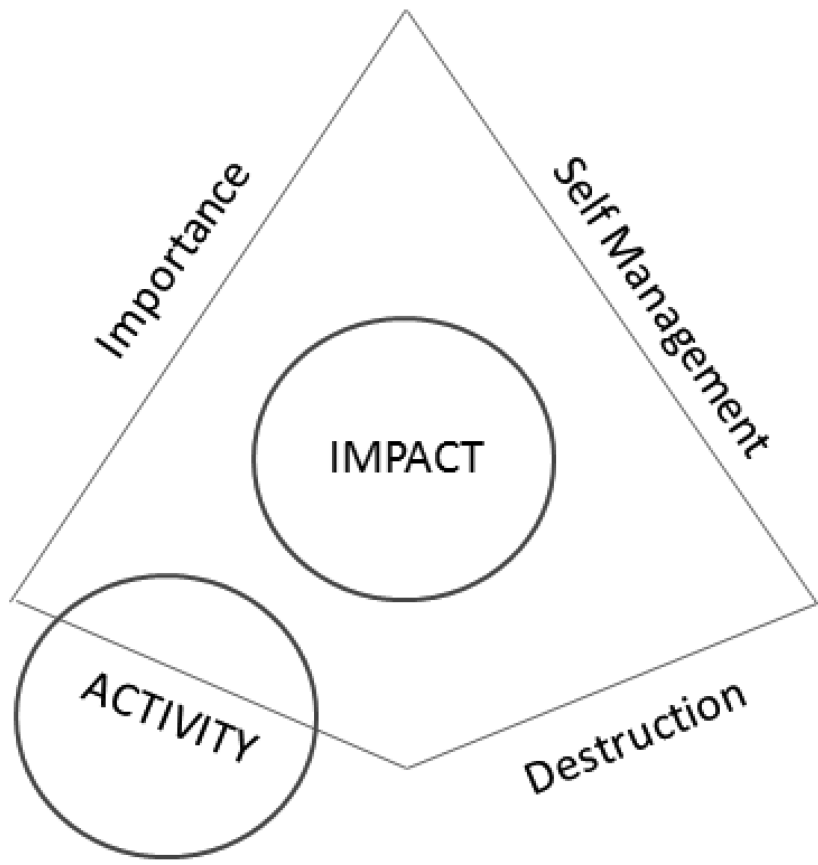

Figure 2. A conceptual framework for composite measures of activity and impact in psoriatic arthritis. From Sanderson, et al. J Rheumatol 2011;38:191-4; modified with permission ${ }^{13}$.

$$
\text { Personal non-commercial use only. The Journal of Rheumatology Copyright (C) 2017. All rights reserved. }
$$


destruction to impact and the conceptual rationale for separate measurement of activity.

Conceptually dividing activity from destruction does not imply that measures of impact cannot be sensitive to change and act as surrogate measures of activity. Data from the original PsAID ${ }^{3}$ study and the RAID ${ }^{15}$ indicate that the tools may well be responsive to change. Indeed, in the cross-sectional study by Di Carlo, et al, the results support correlation of DAPSA disease activity states and PsAID scores. The proposed framework serves only to clarify how measures of impact and activity interrelate.

What is the current state of composite outcome measurement in PsA? The study by Di Carlo, et al supports the validity of the PsAID in PsA in a real-world cohort. Further work is required to gain a fuller understanding of how the PsAID performs in terms of responsiveness, validation of the PsAID subscores, and finally, confirmation of proposed disease effect cutpoints. These can be achieved with larger, longitudinal cohorts with longitudinal data and with anchors of destruction such as radiographic damage. Consensus is needed on which composite disease activity measure to take forward; however, using the framework suggested herein, there is a rationale in studies of PsA for measuring effect and activity concurrently but separately.

WILLIAM TILLETT, $\mathrm{BSc}, \mathrm{MBChB}, \mathrm{PhD}, \mathrm{MRCP}$, Royal National Hospital for Rheumatic Diseases, Upper Borough Walls, and

Department of Pharmacy and Pharmacology, University of Bath, Bath, UK.

Address correspondence to Dr. W. Tillett, Royal National Hospital for Rheumatic Diseases, Upper Borough Walls, Bath, BA1 1RL, UK. E-mail:w.tillett@nhs.net

\section{REFERENCES}

1. de Wit M, Campbell W, Coates LC, Gladman DD, James J, Lindsay CA, et al. Let's talk about inclusion: a report on patient research partner involvement in the GRAPPA 2015 annual meeting. J Rheumatol 2016;43:970-3.

2. Mease PJ. Measures of psoriatic arthritis: Tender and Swollen Joint Assessment, Psoriasis Area and Severity Index (PASI), Nail Psoriasis Severity Index (NAPSI), Modified Nail Psoriasis Severity Index (mNAPSI), Mander/Newcastle Enthesitis Index (MEI), Leeds Enthesitis Index (LEI), Spondyloarthritis Research Consortium of Canada (SPARCC), Maastricht Ankylosing Spondylitis Enthesis Score (MASES), Leeds Dactylitis Index (LDI), Patient Global for Psoriatic Arthritis, Dermatology Life Quality Index (DLQI), Psoriatic Arthritis Quality of Life (PsAQOL), Functional Assessment of Chronic Illness Therapy-Fatigue (FACIT-F), Psoriatic Arthritis Response Criteria (PsARC), Psoriatic Arthritis Joint Activity Index (PsAJAI), Disease Activity in Psoriatic Arthritis
(DAPSA), and Composite Psoriatic Disease Activity Index (CPDAI). Arthritis Care Res 2011;63 Suppl 11:S64-85.

3. Gossec L, de Wit M, Kiltz U, Braun J, Kalyoncu U, Scrivo R, et al; EULAR PsAID Taskforce. A patient-derived and patient-reported outcome measure for assessing psoriatic arthritis: elaboration and preliminary validation of the Psoriatic Arthritis Impact of Disease (PsAID) questionnaire, a 13-country EULAR initiative. Ann Rheum Dis 2014;73:1012-9.

4. Moll JM. Psoriatic arthritis. Br J Rheumatol 1984;23:241-4.

5. Tillett $\mathrm{W}, \mathrm{McHugh} \mathrm{N}$. Treatment algorithms for early psoriatic arthritis: do they depend on disease phenotype? Curr Rheum Rep 2012;14:334-42.

6. Jones SM, Armas JB, Cohen MG, Lovell CR, Evison G, McHugh NJ. Psoriatic arthritis: outcome of disease subsets and relationship of joint disease to nail and skin disease. Br J Rheumatol 1994;33:834-9.

7. Schoels M, Aletaha D, Funovits J, Kavanaugh A, Baker D, Smolen JS. Application of the DAREA/DAPSA score for assessment of disease activity in psoriatic arthritis. Ann Rheum Dis 2010; 69:1441-7.

8. Mumtaz A, Gallagher P, Kirby B, Waxman R, Coates LC, Veale JD, et al. Development of a preliminary composite disease activity index in psoriatic arthritis. Ann Rheum Dis 2011;70:272-7.

9. Sørensen J, Hetland ML. Decreases in diagnostic delay are supported by sensitivity analyses. Ann Rheum Dis 2014;73:e45.

10. Coates LC, Fransen J, Helliwell PS. Defining minimal disease activity in psoriatic arthritis: a proposed objective target for treatment. Ann Rheum Dis 2010;69:48-53.

11. Di Carlo M, Becciolini A, Lato V, Crotti Ch, Favalli EG, Salaffi F. The 12-item Psoriatic Arthritis Impact of Disease Questionnaire: construct validity, reliability, and interpretability in a clinical setting. J Rheumatol 2017;44:279-85.

11a. Gossec L, Dougados M, Rincheval N, Balanescu A, Boumpas DT, Canadelo S, et al. Elaboration of the preliminary Rheumatoid Arthritis Impact of Disease (RAID) score: a EULAR initiative. Ann Rheum Dis 2009;68:1680-5.

12. de Wit MP, Kvien TK, Gossec L. Patient participation as an integral part of patient-reported outcomes development ensures the representation of the patient voice: a case study from the field of rheumatology. RMD Open 2015;1:e000129.

13. Brikman S, Furer V, Wollman J, Borok S, Matz H, Polachek A, et al The effect of the presence of fibromyalgia on common clinical disease activity indices in patients with psoriatic arthritis: a cross-sectional study. J Rheumatol 2016;43:1749-54.

14. Sanderson TC, Hewlett SE, Flurey C, Dures E, Richards P, Kirwan JR. The impact triad (severity, importance, self-management) as a method of enhancing measurement of personal life impact of rheumatic diseases. J Rheumatol 2011;38:191-4.

15. Dougados M, Brault Y, Logeart I, van der Heijde D, Gossec L, Kvien T. Defining cut-off values for disease activity states and improvement scores for patient-reported outcomes: the example of the Rheumatoid Arthritis Impact of Disease (RAID). Arthritis Res Ther 2012;14:R129.

J Rheumatol 2017;44:268-70; doi:10.3899/jrheum.161544 